IZA DP No. 6087

Strategic Ignorance in Bargaining

Julian Conrads

Bernd Irlenbusch

October 2011

Forschungsinstitut zur Zukunft der Arbeit Institute for the Study of Labor 


\title{
Strategic Ignorance in Bargaining
}

\author{
Julian Conrads \\ University of Cologne \\ Bernd Irlenbusch \\ University of Cologne, \\ London School of Economics and IZA
}
Discussion Paper No. 6087
October 2011

\author{
IZA \\ P.O. Box 7240 \\ 53072 Bonn \\ Germany \\ Phone: +49-228-3894-0 \\ Fax: +49-228-3894-180 \\ E-mail: iza@iza.org
}

\begin{abstract}
Any opinions expressed here are those of the author(s) and not those of IZA. Research published in this series may include views on policy, but the institute itself takes no institutional policy positions.

The Institute for the Study of Labor (IZA) in Bonn is a local and virtual international research center and a place of communication between science, politics and business. IZA is an independent nonprofit organization supported by Deutsche Post Foundation. The center is associated with the University of Bonn and offers a stimulating research environment through its international network, workshops and conferences, data service, project support, research visits and doctoral program. IZA engages in (i) original and internationally competitive research in all fields of labor economics, (ii) development of policy concepts, and (iii) dissemination of research results and concepts to the interested public.
\end{abstract}

IZA Discussion Papers often represent preliminary work and are circulated to encourage discussion. Citation of such a paper should account for its provisional character. A revised version may be available directly from the author. 


\section{ABSTRACT}

\section{Strategic Ignorance in Bargaining}

In his classic article "An Essay on Bargaining" Schelling (1956) argues that ignorance might actually be strength rather than weakness. We test and confirm Schelling's conjecture in a simple take-it-or-leave bargaining experiment where the proposer can choose between two possible offers. Option A always gives the proposer a higher payoff than option B. The payoff of the responder depends on the (randomly determined) state of nature, i.e., in state $s_{2}$ payoffs of the two players are aligned while they are not in state $s_{1}$. The responder is always informed about the actual state. The proposer knows the actual state in our first treatment but not in the second. We find that proposers indeed benefit from ignorance because the responders accept almost all offers (even the unfavorable ones) if the payoffs of the responder have not been transparent for the proposer. In additional treatments we investigate situations where the proposer can deliberately remain ignorant. One could assume that remaining ignorant on purpose would be punished by the responder at least if an unfavorable outcome results. Surprisingly, we find that strategically remaining ignorant tends to be beneficial for the proposer particularly if the responder does not know with certainty whether it was the proposer's intention to remain ignorant or whether it was not her intention.

JEL Classification: $\quad$ C72, C78, C91, D63, D82, D83

Keywords: strategic ignorance, bargaining, intentions, experiment

Corresponding author:

Bernd Irlenbusch

University of Cologne

Department of Corporate Development and Business Ethics

Albertus-Magnus-Platz

50939 Cologne

Germany

E-mail: bernd.irlenbusch@uni-koeln.de

\footnotetext{
* We thank Caroline Martens, Frauke Meyer and Katrin Recktenwald for excellent research assistance. Financial support from the Deutsche Forschungsgemeinschaft through grant 'TP3 Design of Incentive Schemes within Firms: Bonus Systems and Performance Evaluations' (sub-project of the DFGForschergruppe 'Design and Behavior') and through the Leibniz-Award to Axel Ockenfels is gratefully acknowledged.
} 
"We don't wanna know [...] We don't want to know what's really going on."

John Davis, "Do the Vampire”, Superdrag, 1998

\section{Introduction}

Information about an opponent's bargaining position plays an important role in negotiations and it not only affects the own bargaining behavior but also the behavior of an opponent. Generally it is assumed that the more information is at hand about a bargaining situation, the better the bargaining position. But Schelling (1960) challenged this view by arguing that a bargainer incompletely informed about his opponent's payoff structure might have an advantage because the completely informed opponent would be forced to make concessions to avoid a bargaining breakdown. In his chapter on "Strategic Moves" Schelling notes that “(...) ignorance can be an advantage to a player if it is recognized and taken into account by an opponent" (Schelling, 1960, p.161). Since the informed bargainer knows that the uninformed one is not aware of what a reasonable solution would be, the responsibility of avoiding a stalemate is a burden on the informed bargainer. Early experimental studies seem to support this view (Siegel \& Fouracker, 1960, Hamner \& Harnett, 1975). The following simple example illustrates the basic intuition: Two persons walking on a crowded main street are going to clash into each other. One of the persons anticipates this upcoming event but the other one is unaware, for example, due to a distraction. The person aware of the possible clash clears the way accepting the "cost" of leaving his ideal route. The (unintentionally) ignorant person just perfectly walks his way. Being uninformed pays off. Ignorance might even be used strategically. A person who anticipates that a clash could happen might just walk through the street looking at the ground pretending to be ignorant. The other informed person has to bear the costs of avoiding the clash, although he might have the feeling that the ignorant person intentionally avoided to look up. Thus, remaining strategically ignorant might pay off. Putting this to an organizational context, one might think of a business partnership. At one day an urgent request comes in but only one of the two partners is in the office. Subtasks have to be allocated quickly between the two partners and the nature of the tasks prohibits re-allocation afterwards. By deliberately remaining ignorant and not 
asking the partner about his preferences, the partner in the office can pick her preferred subtasks and leave the other subtasks to her partner. Should it turn out that the partner dislikes the subtasks allocated to him, she can come up with the excuse: "Oh sorry, I didn't know". The excuse might still have some force despite the fact that in principle she could have informed herself - or at least tried to do so - for example, by calling her partner by phone. ${ }^{1}$

The aim of this study is to experimentally test Schelling's conjecture in a simple two-person take-it-or-leave-it bargaining game. As it is particularly difficult to observe (strategic) ignorance in bargaining in the field, we chose an experimental approach that allows for perfect monitoring of actions including those by which one tries to avoid acquiring information. The most important advantage of an experimental study is control (see Roth 1995, Falk \& Fehr, 2003) which is essential for our purpose, i.e., drawing conclusions about how strategic ignorance causally affects behavior. Moreover, in comparison to questionnaire studies it is possible to provide participants with incentives which are likely to be crucial for the influence of strategic ignorance in bargaining. Our basic experimental framework comprises a simple situation that is reduced to the very essentials of strategic ignorance. One out of two states of nature is determined by a 50:50 draw. While in state $s_{1}$ interests of a proposer and a responder are in conflict, they are aligned in state $s_{2}$. The proposer has to offer one out of two options, option $A$ or option $B$. In state $s_{1}$, the proposer profits from option $A$ more than the responder. Option $B$ in state $s_{1}$ would almost equalize both players' payoffs, but this option is slightly inferior for the proposer in comparison to option $A$. In state $s_{2}$ with aligned interests, option $A$ provides both players with higher payoffs than option $B$. The responder can accept the offer proposed or he can reject it. Accepting an offer always leads to positive payoffs for both players while rejection leaves them with payoffs of zero.

In the treatment Transparency both players are fully informed about the true state. We observe that proposers are not able to always implement their most preferred option.

\footnotetext{
${ }^{1}$ Fischbacher and Utikal (2010) analyze the effectiveness of apologies in preventing punishments after harmful offenses. They find that excuses are not accepted if the harmdoer commits offenses intentionally. If the intention of an offense is not clear, i.e., if the situation is ambiguous, apologies seem to be an effective instrument to reduce the likelihood of being punished. In our context, remaining ignorant blurs the intentionality of the proposer and thereby might reduce the likelihood of being punished through a rejection.
} 
Unfavorable offers are rejected frequently. In the Non-Transparency treatment the proposer is ignorant about the true state but the responder knows. This is shared knowledge among the players. We hypothesize that the proposer will benefit from being ignorant as the responder will accept almost all offers even unfavorable ones. As the experimental results show, the ignorant proposer can indeed almost always implement her most preferred option, i.e., option $A$. One way to explain these results might be differences in causal attributions on outcomes. If an offer is attributable to a chance-based source (i.e., the random incidence of one of the two states of nature) responders accept even unfavorable offers because negative intentions were not involved (e.g. see Blount, 1995, and Falk, Fehr and Fischbacher, 2008).

In a third treatment, Choice, the proposer can choose between remaining ignorant about the occurring state or to reveal the state. Both alternatives incur no direct monetary costs. The idea to introduce a possibility to remain strategically ignorant about the opponent's payoff is adapted from Dana, Weber and Kuang (2007), who analyze the strategic use of ignorance in a dictator game setup. In their game the dictator can remain ignorant to justify a selfish action in front of herself. In our setting not to reveal the state also allows the proposer to go for the self-interested offer (i.e., option $A$ ) without knowing whether this proposal is unfavorable to the responder. Knowing the state would potentially put some (internal) pressure on the proposer to decide for the more equalizing option $B$ in state $s_{1}$. Additionally, by remaining ignorant the proposer might want to influence the responder's inclination to accept an unfavorable offer. The responder is always informed about the actual state and he also learns whether the proposer chose to remain ignorant or not. We hypothesize that proposers will not benefit from strategic ignorance as responders will perceive the act of remaining ignorant as hostile. Surprisingly, our results show that responders tend to reject unfavorable proposals less often when the proposers remain ignorant. To push the idea of the perception of hostile intentions a bit further we designed a modified version of the Choice treatment, Choice Uncertain Revelation, where the intention to reveal is only successful in $50 \%$ of the cases. As a consequence if the proposer remains ignorant, the responder does not know whether this ignorance emerged on purpose or not. We find that responders significantly more often accept unfavorable offers from ignorant proposers than from proposers who 
successfully revealed the state. In a fifth treatment, Choice Hidden, the responder is not informed whether the proposer revealed the state or not. Here few proposers remain ignorant and responders quite often accept unfavorable offers.

The paper is organized as follows. We start by discussing the literature related to strategic ignorance. Secondly, we elaborate our experimental design and derive our hypotheses. In section five we report the experimental results. Finally, section six discusses the results in the light of previous findings and concludes.

\section{Related Literature}

Proctor and Schiebinger (2008, p.3) emphasize the omnipresence of ignorance from an epistemic perspective and differentiate between "ignorance as native state (or resource), ignorance as lost realm (or selective choice), and ignorance as a deliberately engineered and strategic play (or active construct)". Despite the relevance of strategic ignorance in human interactions, the literature on this topic in bargaining is relatively small. Some experimental studies have indicated that negotiators might not profit from being uninformed. For example, Roth and Murnighan (1982) showed that varying information asymmetries between negotiators has an impact on how a pie is split up, i.e.,

uninformed negotiators tend to be exploited by their informed opponents. Negotiators made lower offers if they knew that their opponent was unaware about the actual pie size. Being ignorant turned out to be a disadvantage (see also Kagel, Kim and Moser, 1996).

Other experimental investigations, however, have shown that ignorance might be an advantage. A seminal study of the role of ignorance in bargaining was conducted by Siegel and Fouraker (1960). In their bilateral bargaining experiment the buyer knew the payoff tables of both sides but the seller only knew his own payoff table. Buyer and seller then had to come up with a price-quantity agreement. Although their results were not significant, the authors identified a clear tendency that the incompletely informed participant was better off than his informed opponent. Siegel and Fouraker argued that the incompletely informed bargainer established a higher aspiration level as he was not able to form realistic expectations and therefore made larger demands, smaller concessions and accepted longer durations to reach an agreement. A follow up study by Hamner and Harnett (1975) showed a similar effect. Beisecker, Walker and Bart (1989) 
also examined a complete-incomplete information situation with a fictitious bargaining task. Their results show that an uninformed bargainer can profit from ignorance when his counterpart perceives the own advantage as a violation of procedural equity. To restore relational equity, the completely informed bargainer may accept less favorable agreements. In sum, this strand of literature suggests that it can indeed be an advantage to be ignorant in bargaining. None of these studies, however, examine the possibility to strategically choose to remain ignorant.

More recently, Poulsen and Roos (2010) examined the effect of strategic information avoidance in a Nash demand game where two players had to negotiate about the distribution of an amount of money. At the beginning, the responder had to decide whether or not he wanted to learn about a demand a proposer claimed. The proposer was informed about the responder's decision, before stating his demand. In the repeated setting responders learned that more information may hurt, i.e., over time, informationavoidance increased and the distribution of the surplus became more balanced. In an ultimatum game setup, Poulsen and Tan (2007) let the responder choose his Minimum Acceptable Offer (MAO). The proposer could then costlessly acquire the information about the responder's MAO before making his proposal. The offer was accepted or rejected according to the previously stated MAO. It turned out that one third of the proposers remained uninformed and offered half of the pie. Information-acquiring proposers set offers equal to the responders' MAOs. In a treatment without informationacquisition, the MAOs stated by the responders were smaller compared to the information-acquisition treatments showing that the opportunity of gathering information about the MAOs may backfire for the informed party. Thus in these two studies one player had the chance to remain ignorant about the other player's strategic choice. In our study proposers are able to remain ignorant about the consequences the own offer has on the payoff of the other player. In a similar vain Gehrig, Güth and Levinský $(2003,2006)$ examined a situation in which a proposer could purchase information about a responder's outside option in an ultimatum game. Under transparent information acquisition, where the responder knew whether the proposer was informed, acceptance rates were higher than in non-transparent situations. 
As already mentioned above, our experimental design is also influenced by the dictator game setup of Dana, Weber and Kuang (2007). The aim of their study was to analyze whether generosity in dictator game-giving is truly evidence of the concern for desirable social outcomes. They showed that when the dictator had the opportunity not to know whether his action hurt the receiver or not, many dictators chose a "moral wiggle room" and made self-interested choices. Dana et al. concluded that dictators were more concerned with seeming fair to themselves than to really being fair (see also Dana, Cain and Dawes, 2006, and Broberg, Ellingsen and Johannesson, 2007).

\section{Experimental Design and Procedures}

\subsection{A Simple Model of Strategic Ignorance in Bargaining}

We consider a situation in which a random move selects one of two possible states of nature, $s_{1}$ and $s_{2}$, which occur with equal probability. This is known to all players. A proposer $(P)$ makes a take-it-or-leave-it-offer to a responder $(R)$ by choosing between two possible options, option $A$ and option $B$. The responder has to decide about accepting or rejecting the offer. Rejection leaves both players with zero payoffs. Accepted options provide both players with strictly positive payoffs. An accepted option $A$ pays more to the proposer than an accepted option $B$. Whether an accepted option $A$ is more preferable from the responder's perspective than an accepted option $B$ depends on the actual state of nature. In state $s_{1}$ the responder's payoff from option $B$ is higher than from option $A$. In state $s_{2}$ it is the other way round. Thus, in state $s_{2}$ the payoffs of the two players are aligned, i.e., option $A$ is the preferred option of both players, while in state $s_{1}$ they are not aligned. In the following we call an offer of option $A$ in state $s_{1}$ an unfavorable offer for the responder and option $B$ in state $s_{1}$ a favorable one. Figure 1 shows the game tree with the exact payoff details. ${ }^{2}$ Our five treatments build on this baseline game. In all of our treatments the responder knows the actual state of nature when he decides on accepting or rejecting the proposed offer. Treatments differ in what the proposer knows or can learn

\footnotetext{
2 We basically use the same payoff parameters as Dana et al. (2007) in their dictator game but reduce the option $B$ payoff of the proposer. This makes option $A$ in state $s_{1}-$ in which the payoffs of the two players are not aligned - slightly more attractive for the proposer, i.e., in the Choice treatments (see below) the proposer might be more inclined to remain ignorant. For completeness the game trees for the other treatments are provided in the appendix.
} 
about the actual state of nature before making the offer. We also vary what the responder knows about what the proposer knew when making the offer. In the following we introduce the details of our five treatments.

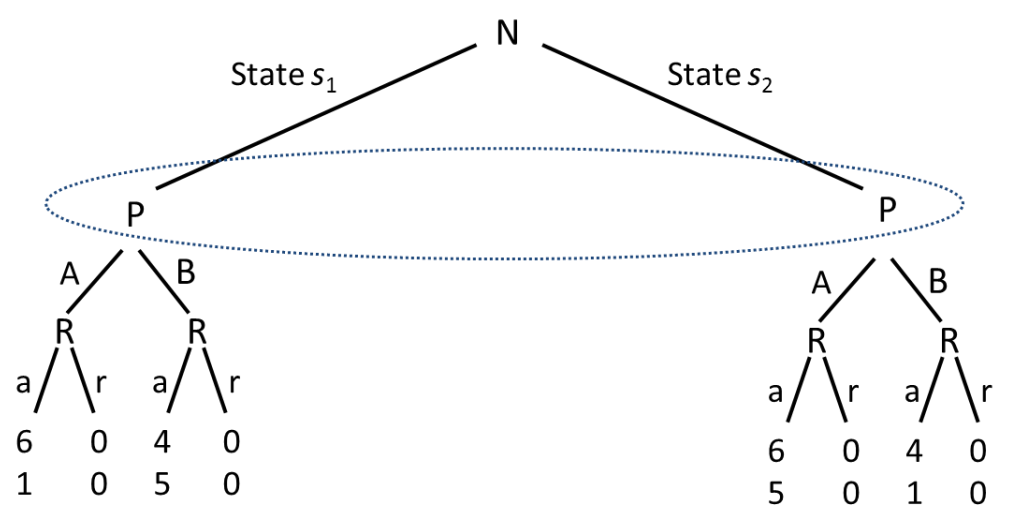

Figure 1: Tree of the game employed in the Transparency treatment (without the dotted-line information set of $P$ ) and in the Non-Transparency treatment (including the dotted-line information set of $P$ ). The number at the top denotes the payoff of the proposer while the number at the bottom is the payoff of the responder

\subsection{Treatments}

In our first treatment, Transparency, we employ the game depicted in Figure 1 without the dotted-line information set of the proposer, i.e., the proposer knows the actual state of nature when she makes the offer. Our second treatment, Non-Transparency, includes the dotted-line information set, i.e., the proposer is not aware of the true state of nature when making her offer. In the third treatment, Choice, we endogenize transparency, i.e., the proposer can choose between a transparent situation and a nontransparent one. The proposer can reveal the actual state of nature or she can remain ignorant both at no costs. Then she decides on the offer. Before the responder accepts or rejects the offer he learns whether the proposer revealed the actual state of nature or not, i.e., the responder becomes aware of whether an unfavorable offer has been made knowingly or whether it has been made in the dark. Building on the game used in treatment Choice, in two other treatments we relax the assumption that the responder is informed about what the proposer knew when making the offer. In the fourth treatment, Choice Uncertain Revelation (henceforth Choice-UR), it is uncertain whether the proposer will be successful with her attempt to reveal the true state of nature. If she chooses to remain ignorant she remains ignorant for sure. If she chooses to reveal, 
revelation is not certain but there is a $50 \%$ chance that revelation is successful, i.e., she learns about the true state of nature with a 50:50 chance. Otherwise she remains ignorant. The responder is informed whether or not the proposer knew the actual state of nature when she made the offer. If the proposer was informed it is clear for the responder that the proposer chose to reveal and that her attempt was successful. If the responder learns that the proposer was not informed, it might be due to two different reasons. First, the proposer did not want to know. Or, second, she actually wanted to know but was not successful in revealing the information. Thus, in the latter case the responder cannot be sure about the actual intentions of the proposer, i.e., whether she tried to reveal or not. In our fifth treatment, Choice Hidden (henceforth Choice-H), the responder is kept uninformed about whether the proposer revealed the actual state of nature or not.

\subsection{Procedures}

The experimental sessions took place at the Cologne Laboratory for Economic Research (CLER) from August 2010 to April 2011. Subjects were recruited by the online recruitment system programmed by Greiner (2004). Overall we had 592 participants (289 female) who were randomly drawn from a subject pool of over 3.000. Each session involved 16 to 32 participants and they were not allowed to take part in more than one session. About half of the participants were majoring in economics or business administration, the other half was enrolled in different fields like law and sciences. On average, participants were in their fourth year of studies. We conducted two sessions of the Transparency, the Non-Transparency and the Choice-H treatment, respectively. Since potential variations of plays are larger in the other two treatments we ran six sessions of the Choice and eight sessions of the Choice-UR treatments.

At the beginning of a session, participants were randomly allocated to cubicles. After they had been seated, written instructions were distributed. Within a session, all subjects received the same instructions. Instructions of different treatments were kept exactly the same with the exception of well-defined passages that described the treatment variations (see appendix). Each participant learned that he would play a simple one-shot game by interacting with one other person in the room who was randomly and 
anonymously matched to him. Before a session started, subjects had to answer a pen and paper quiz to confirm that they had understood the game (see appendix for the quiz).

The experiment was computerized using Fischbacher's zTree software (2007). Participants were informed about their randomly assigned roles on the first screen. We neutrally labeled a proposer as "participant $X$ " and a responder as "participant $Y$ ". The two states of nature were denoted by "Case 1" and "Case 2", respectively. In the treatments Transparency and Non-Transparency a proposer just had to choose between option $A$ or option $B$. In addition in the other three treatments a proposer had to decide on whether to reveal the true state of nature or not. As mentioned above a responder always learned about the true state of nature before deciding on accepting or rejecting the offer. To collect more data on the responders' behavior we requested their decisions by a reduced version of the strategy method (Selten, 1967) ${ }^{3}$, i.e., the responder was not asked for a complete strategy but had to decide whether - given the actual state of nature - he would be willing to accept or reject option $A$ and option $B$.

To gain deeper insights into subjects' preferences and motivations, we asked them about their beliefs regarding the behavior of the other player and about their decisions on hypothetical situations after subjects had completed their decisions (and before they learned about those of the other player). The hypothetical situations dealt with a different treatment or a different state of nature. In the Transparency and Non-Transparency treatments, we asked the proposer and the responder to imagine that they had to decide in the same role but in the situation of the other treatment, respectively. In the Choice treatments, we asked subjects to imagine that the opposite decision regarding the revelation of the true state of nature had been taken. For example, we asked a proposer, who actually decided to remain ignorant, which option, $A$ or $B$, she would have offered, had she revealed the actual state.

At the end of each session subjects were informed about the decisions of the other player they were matched with and about their payoffs. Afterwards they were requested to fill in a questionnaire asking subjects to briefly explain the motivation of their decisions. Finally participants were privately paid their payoffs from the game in addition

\footnotetext{
${ }^{3}$ There is no clear evidence on whether employing the strategy method or not leads to differences in behavior. On this "hot-or-cold" debate see for example Brandts und Charness (2011).
} 
to an individual show-up fee of $€ 2.50$. On average participants earned $€ 7.04$ and sessions lasted for approximately 35 minutes.

\section{Hypotheses}

Assuming that it is common knowledge that the two bargainers are purely interested in maximizing their own payoffs, the responder should accept both offers in both states of nature, irrespective of whether the proposer revealed the true state of nature or not. Thus, the proposer could safely offer option $A$ since this option yields him a higher payoff in both states of nature. However, we know from many experiments on the ultimatum game and other games that proposers offer more than just the smallest positive amount (see, for example, Güth, Schmittberger, Schwarze, 1982 and Camerer, 2003). This seems to be partly driven by the proposer's concerns for (distributive) fairness. ${ }^{4}$ Partly, it is because responders are willing to reject unfair offers and/or offers that signal bad intentions of the proposer (see Blount, 1995 and Falk, Fehr, Fischbacher 2008).

In the following we mainly concentrate on behavior in state $s_{1}$, which is the more interesting state of nature as in this state payoffs of the two players are not aligned, i.e., option $A$ yields higher payoffs for the proposer but is less equitable and provides the responder with smaller payoffs than option $B$. In state $s_{2}$ payoffs are aligned and it can safely be assumed that option $A$ will be proposed and accepted. Our hypotheses and their rationales are summarized in Table 1.

\footnotetext{
4 Models of social preferences can partly explain such behaviour. For prominent models of inequityaversion, see Levine (1998), Fehr und Schmidt (1999) and Bolton und Ockenfels (2000). The influence of intentions is modelled in (Falk und Fischbacher, 2008). Concerns for efficiency might also play a role in our setting (Charness und Rabin, 2002). See also the finding on mini-ultimatum games that employ a reduced strategy set - often two strategies - for the proposer (see, for example, Bolton and Zwick, 1995, Güth, Huck, und Müller, 2001, Falk, Fehr, and Fischbacher, 2003).
} 
Treatment

Transparency

Non-Transparency

Choice

- A considerable number of proposers offer option in state $s_{1}$.

Rationale: Proposers might be concerned about distributive fairness and/or fear responders' rejection of option $A$.

- Proposers almost always offer option $A$.

Rationale: Proposers earn more with option $A$ and they have no reason to believe that option $B$ is better for the responder.

- Virtually all proposers reveal the state of nature. Rationale: When remaining ignorant proposers risk to offer an unfavorable option $A$ (if the actual state is $s_{1}$ ).

- Proposers who reveal the state of nature to be $s_{1}$ offer the favorable option to the responder, i.e., option $B$.

Rationale: Proposers might be concerned about distributive fairness and/or fear responders' rejection of option $A$.

\section{Hypotheses on Responders' Behavior}

- In state $s_{1}$ a substantial proportion of responders reject option $A$ while option $B$ is virtually always accepted.

Rationale: Some responders might prefer zero payoffs for both players to accepting the unfavorable option $A$ in state $s_{1}$

- Irrespective of the true state of nature responders tend to accept all offers. Rationale: Responders are aware of the fact that proposers do not know the actual state of nature. Thus, even an unfavorable offer of option $A$ in state $s_{1}$ is not seen as badly intended.

- Unfavorable offers proposed by ignorant proposers are not more often accepted than unfavorable offers from informed proposers.

Rationale: Proposing an unfavorable offer after deliberately having remained ignorant is considered as equally badly by the responder as knowingly doing so.

- Virtually all proposers try to reveal the true state of nature. Rationale: When remaining ignorant proposers risk to offer an unfavorable option $A$ (if the actual state is $s_{1}$ ).

Choice Uncertain Revelation

- Proposers who successfully reveal the state to be $s_{1}$ offer the favorable option most of the time, i.e., option $B$.

Rationale: Proposers might be concerned about distributive fairness and/or fear responders' rejection of option $A$.
- In comparison to Choice a larger proportion of responders accept an unfavorable offer in state $s_{1}$ from ignorant proposers.

Rationale: An ignorant proposer might have tried to reveal the state. Thus, being ignorant and making an unfavorable offer in state $s_{1}$ might not be badly intended.

- Unfavorable offers are accepted similarly often as in Choice. Rationale: Proposing an unfavorable offer after deliberately having remained ignorant is considered as equally badly by the responder as knowingly doing so.

Choice Hidden

- Virtually all proposers reveal the state of nature. Rationale: When remaining ignorant proposers risk to offer an unfavorable option $A$ (if the actual state is $s_{1}$ ).

- Proposers who reveal the state of nature to be $s_{1}$ offer the favorable option to the responder, i.e., option $B$.

Rationale: Proposers might be concerned about distributive fairness and/or fear responders' rejection of option $A$.

Table 1: Hypotheses on the proposers' and responders' behavior in the five treatments with a focus on state $s_{1}$ 


\section{Results}

In a first step we will discuss the results from the Transparency and NonTransparency treatments. Then we present our findings from the three Choice treatments in which subjects can deliberately remain ignorant.

\subsection{Results Transparency and Non-Transparency}

Table 2 summarizes the results from the Transparency and Non-Transparency treatment. In Transparency 9 out of 16 proposers (56\%) offered option $A$ in state $s_{1}$. In

\begin{tabular}{cccccc}
\hline \hline & & \multicolumn{2}{c}{ State $\boldsymbol{s}_{\mathbf{1}}$} & \multicolumn{2}{c}{ State $\boldsymbol{s}_{\mathbf{2}}$} \\
\hline & & Option $\boldsymbol{A}$ & Option $\boldsymbol{B}$ & Option $\boldsymbol{A}$ & Option $\boldsymbol{B}$ \\
\hline $\begin{array}{c}\text { Transparency } \\
(n=64)\end{array}$ & Proposals & $9 / 16(56 \%)$ & $7 / 16(44 \%)$ & $16 / 16(100 \%)$ & $0 / 16(0 \%)$ \\
\hline $\begin{array}{c}\text { Non- } \\
\text { Transparency } \\
(n=64)\end{array}$ & Acceptance Rates & $11 / 16(69 \%)$ & $16 / 16(100 \%)$ & $16 / 16(100 \%)$ & $10 / 16(63 \%)$ \\
\hline \hline
\end{tabular}

Table 2: Results from Transparency and Non-Transparency; note that in the treatment Non-Transparency the 32 proposers are not aware of the actual state

state $s_{2}$ all 16 proposers offered option $A$. In reply to these proposals, 11 out of 16 responders (69\%) accepted option $A$ in state $s_{1}$. As expected the favorable option $B$ was always accepted $(16 / 16,100 \%)$ in state $s_{1}$. In state $s_{2}$, option $A$ was always accepted $(16 / 16,100 \%)$ and option $B$ would have been accepted by 10 out of 16 proposers $(63 \%) .^{5}$ In Non-Transparency all but two out of the 32 proposers offered option $A$. 15 out of 16 responders (94\%) accepted option $A$ in state $s_{1}$ and 14 out of $16(88 \%)$ agreed to option $B$ in state $s_{2}$. The favorable option in state $s_{1}$, i.e., option $B$, was always accepted. The same is true for option $A$ in state $s_{2}$.

Observation 1: In state $s_{1}$ proposers significantly more often offered option A in Non-Transparency than in Transparency. ${ }^{6}$

\footnotetext{
${ }^{5}$ Note that none of the proposers actually offered option $B$ in state $s_{2}$, but since we employed a reduced version of the strategy method responders were asked to provide their responses to both possible offers.

${ }^{6}$ With $p=0.017$ (Fisher-Test, one-sided). This observation is also backed by OLS and probit regressions (see appendix).
} 
Responders reacted differently to unfavorable offers in the two treatment variations.

Observation 2: In state $s_{1}$ responders significantly more often accepted option A in Non-Transparency than in Transparency. ${ }^{7}$

Thus, our hypotheses concerning both treatments are supported: Proposers who were kept ignorant almost always offered option $A$ and responders tended to accept these offers. Informed proposers in state $s_{1}$ were considerably less often able to implement their most preferred option, i.e., option $A$.

In the treatments Transparency and Non-Transparency it was exogenously determined whether the proposer was informed about the actual state or not, i.e., intentions about remaining ignorant or not did not play a role. Let us now turn to the treatments where ignorance was endogenous, i.e., could be chosen by the proposer.

\subsection{Results Choice Treatments}

In contrast to our hypothesis in the treatments Choice and Choice-UR a considerable number of proposers decided for remaining ignorant. In both treatments $76 \%$ chose to reveal the state. In Choice-UR 53\% of the proposers who tried to reveal the actual state were successful in revealing while the others remained ignorant. In Choice-H $88 \%$ of the proposers revealed the state.

Observation 3: In Choice and in Choice-UR a considerable number of proposers chose to remain ignorant.

Figure 2 shows the percentage of proposers who offered option $A$ in state $s_{1}$ in which the interests of both players were not aligned. The results in state $s_{2}$ were very similar to those in Transparency and Non-Transparency: Proposers almost always offered option $A$ and responders almost always accepted this offer (see also the summary table in the appendix).

\footnotetext{
${ }^{7}$ With $p=0.077$ (Fisher-Test, one-sided). This observation is also backed by OLS and probit regressions (see appendix).
} 


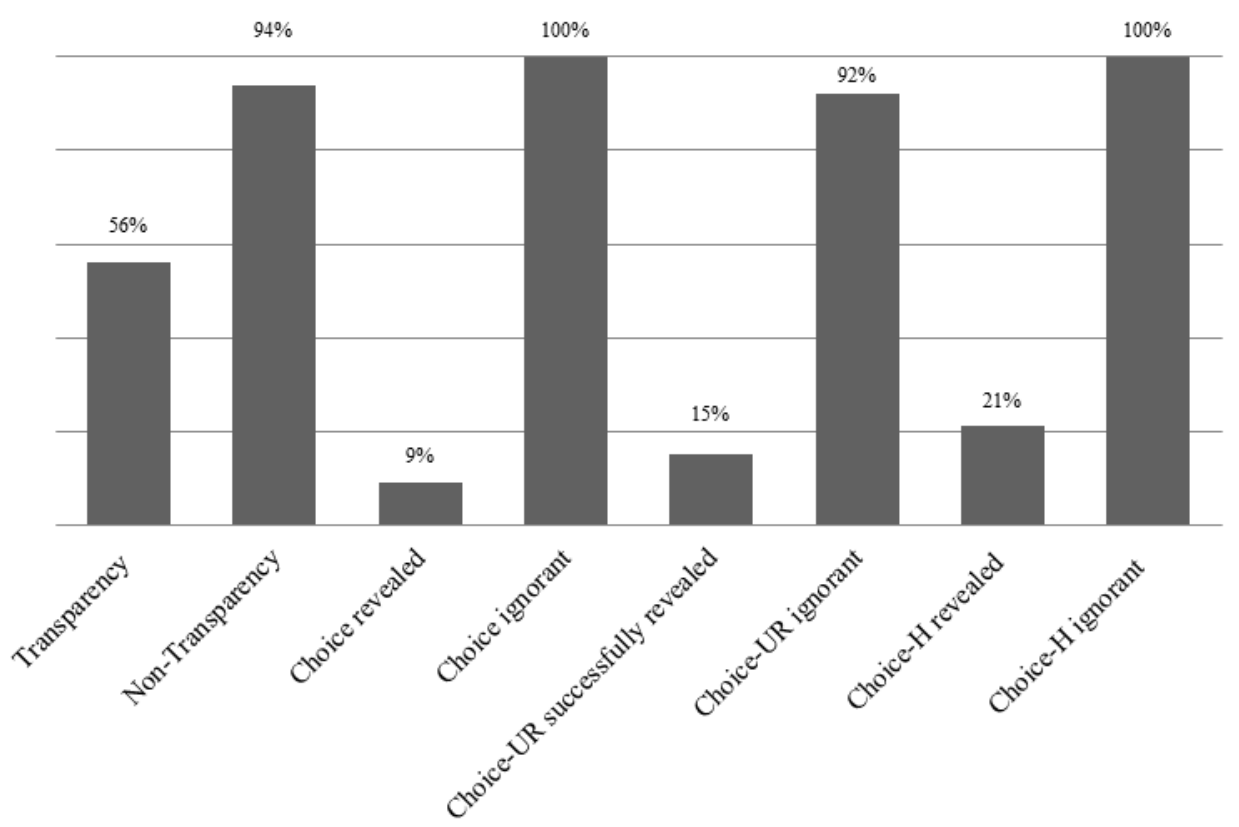

Figure 2: Proportions of proposers offering option $A$ in state $s_{1}$ where the interests of both players are not aligned; note that in Non-Transparency, Choice ignorant, Choice-UR ignorant and Choice-H ignorant proposers are not aware that they actually are in state $s_{1}$

In each of the treatments Choice, Choice-UR and Choice-H 3 of the proposers (in Choice out of 35 proposers, in Choice-UR out of 20 proposers and in Choice-H out of 14 proposers), who (successfully) revealed the actual state to be $s_{1}$, offered option $A$.

Observation 4: In all three Choice treatments, a clear majority of proposers who revealed the state of nature to be $s_{1}$, decided to offer option $\mathrm{B}$.

Proposers who actually were in state $s_{1}$ but decided to remain ignorant in the three Choice treatments significantly more often proposed option $A$ in comparison to situations where proposers revealed the state $s_{1}$ (all significant at the 1\%-Level, Fisher-Tests, one-sided, for each respective Choice treatment). ${ }^{8}$ In the Transparency treatment proposers

\footnotetext{
${ }^{8}$ See also the OLS and probit regressions in the appendix. Here the $p$-values show that compared to Transparency, a significantly smaller proportion of revealing proposers offered option A. Proposers who remained ignorant significantly more often offered option $A$.
} 
significantly more often (56\%) offered option $A$ in state $s_{1}$ than proposers who revealed in the treatments Choice and Choice-UR. ${ }^{9}$

Figure 3 depicts the responders' rates of accepting option $A$ in state $s_{1}$. Again, we focus on the acceptance of option $A$ in state $s_{1}$ where the interests of both players are not aligned. In state $s_{2}$ - not shown here - proposers always offered option $A$ which was almost always accepted by the responders.

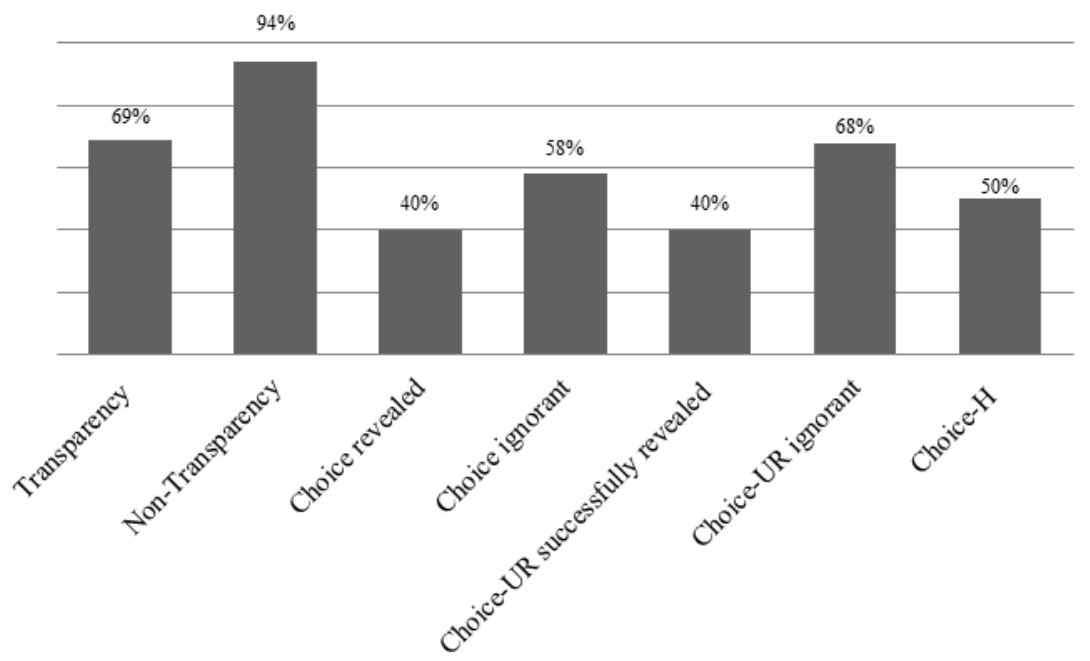

Figure 3: Proportions of responders accepting option $A$ in state $s_{1}$ where the interests of both players are not aligned

In Choice responders knew whether they received an offer from a revealing (Choice revealed) or an ignorant (Choice ignorant) proposer. 14 out of 35 proposers (40\%) accepted option $A$ offered by a revealing proposer. If this offer came from an ignorant proposer it was accepted with a higher frequency, i.e., by 7 out of 12 responders (58\%). Hence, our hypothesis that unfavorable offers from ignorant proposers are evaluated equally badly than offers from proposers who revealed yields only limited support. Responders in Choice-UR knew when a proposer successfully revealed the state of nature. The acceptance rates were identical to Choice, i.e., in Choice-UR 8 out of 20 responders (40\%) accepted option $A$ offered by a proposer who successfully revealed. If proposers in Choice-UR remained ignorant, responders did not know whether this

\footnotetext{
${ }^{9}$ With $p=0.001$ comparing Transparency and Choice, $p=0.02$ comparing Transparency and Choice-UR (Fisher-Tests, two-sided).
} 
ignorance was intended by the proposers or whether the attempt to reveal was not successful. We find that 21 out of 31 responders (68\%) accepted option $A$ offered by ignorant proposers, which is well above the corresponding acceptance rate in Choice ignorant.

Observation 5: In Choice in state $s_{1}$ option A was more often accepted when it was offered by an ignorant proposer than by a proposer who revealed the actual state. In Choice-UR in state $s_{1}$ option A was significantly more often accepted when it was offered by an ignorant proposer than by a proposer who revealed the actual state. $^{10}$

As there was uncertainty about the proposers' intentions to remain ignorant, our hypothesis that unfavorable options offered by ignorant proposers would be more often accepted in Choice-UR than in Choice yields some support although the difference is not significant.

In the Transparency treatment the acceptance of option $A$ in state $s_{1}$ was significantly higher than in Choice and Choice-UR when proposers revealed state $s_{1} \cdot{ }^{11}$ Explicitly revealing the state $s_{1}$ and then offering the unfavorable option (Choice and Choice-UR) seemed to be disliked more by the responders than offering the unfavorable option after having been automatically informed about the state $s_{1}$ (Transparency). In Choice- $H$ the responder was not informed whether the proposer revealed the state of nature or not. In this treatment the acceptance rate for option $A$ in state $s_{1}$ was between those of Choice revealed and Choice ignorant as 8 out of 16 responders (50\%) accepted this offer. The same is true when comparing the acceptance rates of Choice- $H$ and Choice-UR.

${ }^{10}$ Not significant in Choice with $p=0.326$ (Fisher-Test, two-sided) and significant in Choice-UR with $p=0.082$ (Fisher-Test, two-sided).

11 With $p=0.048$ (Fisher-Test, one-sided, pooled data from Choice and Choice-UR). See also the OLS and probit regressions in the appendix. The $p$-values show that compared to Transparency, a significantly smaller share of responders accepted option $A$ offered by proposers who revealed state $s_{1}$. 


\subsection{Hypothetical Decisions and Beliefs in Choice}

We asked non-revealing proposers in Choice what they would hypothetically have done in case they had revealed the state of nature. 12 out of 23 proposers (52\%) would have offered option $A$ in state $s_{1}$. But only 3 out of 35 proposers (9\%) who actually revealed state $s_{1}$ offered option $A$. This difference between proposers who revealed and those who did not is significant ( $p=0.0002$, Fisher-Test, one-sided). A reason might be that proposers who revealed the state of nature were of a more fair-minded type than proposers who chose ignorance.

We also asked proposers who revealed the state of nature whether they believed that option $A$ in state $s_{1}$ offered by a revealing proposer would have been accepted or not.. 40 out of 72 proposers (56\%) thought that such an offer would have been accepted. The same proposers were also asked about their beliefs concerning the acceptance of option $A$ in state $s_{1}$ in case a proposer had chosen ignorance. Here only 26 out of 72 revealing proposers (36\%) believed that this offer would have been accepted. The picture changes when posing the same questions to proposers who did not reveal: 10 out of 23 proposers (43\%) believed that option $A$ in state $s_{1}$ would have been accepted if the proposer had revealed the state of nature. Without revelation 19 out of 23 (82\%) ignorant proposers thought that this offer would have been accepted, which is a significant difference in comparison to revealing proposers $(p=0.004$, McNemar-Test, two-sided $)$. Thus, the beliefs of revealing and non-revealing proposers seemed to reflect their differing perceptions of the effectiveness of ignorance in terms of a potential strategic advantage. ${ }^{12}$

Taking a closer look at the responders' beliefs and hypothetical decisions in the Choice treatment sheds some light on the role of the proposers' intentions. Only 14 out of the 35 responders (40\%) actually accepted option $A$ in state $s_{1}$ offered by a proposer who

\footnotetext{
${ }^{12}$ Asking participants to briefly explain the motivation of their decisions generated interesting insights. A proposer who decided to reveal the state, for example, wrote (translated from German): "I revealed because I wanted to offer option B in case of state $s_{1}$. If I really wanted to offer option A in this state, I would not have revealed to positively influence the responder to accept option A." Another proposer who did not reveal the state of nature commented: "I did not reveal to have an excuse for offering option A in state $s_{l}$. In my opinion the responder then does not think that I am intentionally mean." A responder who received an offer from a proposer who revealed wrote: "I accepted option B in state $s_{1}$ as it is the fair solution for both players. But I did not accept option A because I don't want to accept $€ 6$ for him and only $€ 1$ for me. I decided this way because I knew that the proposer revealed the state. In case the proposer would not have revealed I would have accepted all offers because then chance would have decided and the proposer would not have known what state actually occurred."
} 
revealed. But 21 out of these 35 responders (60\%) would have hypothetically accepted this offer if the proposer had remained ignorant $(p=0.016$, McNemar-Test, two-sided $) .{ }^{13}$ Moreover, 7 out of 12 responders (58\%) accepted option $A$ in state $s_{1}$ when it was offered by an ignorant proposer. Only 4 out of these 12 responders (33\%), however, would have accepted this offer if it had been made by a proposer who revealed the state $s_{1}{ }^{14}$

\section{Concluding Remarks}

The results from the Transparency and Non-Transparency treatments provide support for Schelling's conjecture: Ignorance can indeed be an advantage for proposers. Almost all incompletely informed proposers in Non-Transparency implement their maximum payoff, i.e., €6. Responders seem to acknowledge that their opponents do not know the responders' payoff structure. The high rate of acceptance may be due to the responders' tendency to attribute unfavorable offers to the chance-based source of the randomly occurring state of nature. By doing so the selfish intention of the proposer might be diluted.

In the three Choice treatments there are at least two reasons for a proposer to remain ignorant. The first is that a proposer wants to remain ignorant in front of herself, i.e., she does not want to know what a respective offer exactly means for a responder. A proposer who wants to offer option $A$ may easier feel morally consistent when being ignorant compared to knowing the state as the random draw could be blamed for an outcome that is potentially unfavorable for the responder (see also Dana et al., 2007). However, our observations in the treatment Choice- $H$ indicate that this explanation might not be the only one: In this treatment only very few proposers remain ignorant (in front of themselves) when responders are not informed about the proposer's decision whether to reveal or not. An additional reason for remaining ignorant might be that a proposer strategically uses ignorance. Such a proposer may believe that ignorance increases the

13 Asking this question to all responders who received an offer from a revealing proposer regardless whether they were in state $s_{1}$ or state $s_{2}$ showed that 38 out of 72 responders $(53 \%)$ would have accepted option $A$ in state $s_{1}$ from an ignorant proposer.

14 Asking this question to all responders who received an offer from an ignorant proposer regardless whether they were in state $s_{1}$ or state $s_{2}$ showed that only 8 out of 23 responders (35\%) would have accepted option $A$ from a proposer who revealed state $s_{1}$. 
responder's inclination to accept even unfavorable offers. This second explanation is supported by the proposers' beliefs and also by answers to our open question: Ignorant proposers think that option $A$ in state $s_{1}$ would be less frequently accepted if they had revealed.

Responders seem to differentiate between offers coming from informed or ignorant proposers. One might think that the intention to propose an unfavorable offer is evaluated as equally badly by a responder regardless whether a proposer informed herself or deliberately remained ignorant. Since revealing the state is costless, it could even be argued that remaining intentionally ignorant is a more ruthless behavior of the proposer. The acceptance rates and the hypothetical decisions, however, show that responders are inclined to accept unfavorable offers from intentionally ignorant proposers more often than from proposers who revealed the state. Moreover, unfavorable offers from revealing proposers in each of the Choice treatments are more often rejected than in the Transparency treatment. Responders seem to perceive unfavorable offers by proposers who deliberately revealed state $s_{1}$ (in the Choice treatments) as worse intended than unfavorable offers by proposers who are unintentionally informed about the state $s_{1}$ (in the Transparency treatment).

A crucial question is whether it pays for the proposer to be (strategically) ignorant. When the proposers are kept ignorant in the Non-Transparency treatment they earn significantly more than in the Transparency treatment independently of the occurring state ( $p=0.016$, Mann-Whitney-U-Test, two-sided). In Transparency proposers earn $€ 5.19$ on average compared to $€ 5.69$ in Non-Transparency. In the Choice treatment there is no significant difference between payoffs achieved from informed and ignorant proposers, respectively ( $p=0.158$, Mann-Whitney-U-Test, two-sided). However, with ambiguity about the proposer's intentions in Choice-UR ignorant proposers earn significantly more than proposers who successfully reveal state $s_{1}$ or state $s_{2}(p=0.045$, Mann-Whitney-U-Test, two-sided). Remaining strategically ignorant in this treatment pays off as proposers who reveal earn $€ 4.83$ on average. Ignorant proposers on average make $€ 5.20$.

In this study we find indications that ignorance about an opponent's payoff structure might be an advantage in bargaining. We design a take-it-of-leave-it bargaining 
experiment and observe that both unintended and strategic ignorance can be a source of bargaining strength. Proposers who are kept ignorant about the opponents' actual payoffs are almost always able to implement their most preferred option. Proposers who intentionally choose to remain ignorant about their opponents' bargaining position are more frequently able to realize their payoff-maximizing bargaining solution than proposers who gather information. A remarkable proportion of responders receiving unfavorable offers do not punish ignorant proposers through rejection. Although proposers can costlessly acquire information about payoff consequences, responders do not resent the proposers' ignorance. Hence, Schelling's conjecture (1960) that informational weakness can be strength is supported but also extended: Ignorance can even be used strategically if the opponent is aware of the ignorance.

In the light of our results, research on the strategic use of ignorance in bargaining appears to be undervalued so far. Naturally our experiment uses a specific bargaining format and a specific payoff structure. Further research is needed to verify whether our findings extend to bargaining formats that do not employ anonymous take-it-or-leave-it offers, for example, like sequential offer bargaining or face-to-face settings. It also needs to be investigated how different payoff constellations in the bargaining game affect the success of strategic ignorance. 


\section{References}

Beisecker, T., G. WALKer, and J. BART (1989): "Knowledge Versus Ignorance as Bargaining Strategies: The Impact of Knowledge About Other's Information Level," The Social Science Journal, 26, 161-172.

Blount, S. (1995): "When Social Outcomes Aren't Fair: The Effect of Causal Attributions on Preferences," Organizational Behavior and Human Decision Processes, 63, 131-144.

Bolton, G. E., and A. OCKENFEls (2000): "ERC: A Theory of Equity, Reciprocity, and Competition," The American Economic Review, 90, 166-193.

Bolton, G. E., and R. ZwICK (1995): "Anonymity Versus Punishment in Ultimatum Bargaining," Games and Economic Behavior, 10, 95-121.

BrandTS, J., and G. Charness (2011): "The Strategy Versus the Direct-Response Method: A First Survey of Experimental Comparisons," Experimental Economics, 14, 375-398.

Broberg, T., T. EllingSEn, and M. Johannesson (2007): "Is Generosity Involuntary?," Economics Letters, 94, 32-37.

CAMERER, C. F. (2003): "Behavioural Studies of Strategic Thinking in Games," Trends in Cognitive Sciences, 7, 225-231.

Carpenter, J., E. Verhoogen, and S. Burks (2005): "The Effect of Stakes in Distribution Experiments," Economics Letters, 86, 393-398.

Charness, G., and M. RABIN (2002): "Understanding Social Preferences with Simple Tests," Quarterly Journal of Economics, 117, 817-869.

Dana, J., D. M. CAin, and R. M. DAwes (2006): "What You Don't Know Won't Hurt Me: Costly (but Quiet) Exit in Dictator Games," Organizational Behavior and Human Decision Processes, 100, 193-201.

Dana, J., R. A. Weber, and J. X. KuAng (2007): "Exploiting Moral Wiggle Room: Experiments Demonstrating an Illusory Preference for Fairness," Economic Theory, 33, 67-80.

FALK, A., and E. FEHR (2003): "Why Labour Market Experiments?," Labour Economics, 10, 399-406.

FAlK, A., E. Fehr, and U. FischBAChER (2003): "On the Nature of Fair Behavior," Economic Inquiry, 41, 20-26. 
- (2008): "Testing Theories of Fairness-Intentions Matter," Games and Economic Behavior, 62, 287-303.

FeHR, E., and K. M. Schmidt (1999): "A Theory of Fairness, Competition, and Cooperation," Quarterly Journal of Economics, 114, 817-868.

FischBACHER, U. and U. UtiKal (2010), "On the acceptance of apologies," Research paper Series No.53, University of Konstanz.

FISCHBACHER, U. (2007): "Z-Tree: Zurich Toolbox for Ready-Made Economic Experiments," Experimental Economics, 10, 171-178.

GEHRIG, T. P., W. GÜTH, and R. LEVÍNSKÝ (2006): "(In)Transparency of Information Acquisition: A Bargaining Experiment," C.E.P.R. Discussion Papers, CEPR Discussion Papers: 5817.

GEHRIG, T. P., W. GÜTH, and R. LEVÍNSKÝ (2003): "Ultimatum Offers and the Role of Transparency: An Experimental Study of Information Acquisition," Papers on Strategic Interaction, Max Planck Institute of Economics, Strategic Interaction Group.

GreineR, B. (2004): "An Online Recruitment System for Economic Experiments," in Forschung und Wissenschaftliches Rechnen 2003, Gwdg Bericht 63, ed. by V. M. Kurt Kremer. Göttingen, Germany: Ges. für Wiss. Datenverarbeitung, 79-93.

GÜTH, W., S. HuCK, and W. MÜlleR (2001): "The Relevance of Equal Splits in Ultimatum Games," Games and Economic Behavior, 37, 161-169.

GÜTH, W., R. SCHMitTBERGER, and B. SChWARZE (1982): "An Experimental Analysis of Ultimatum Bargaining," Journal of Economic Behavior \& Organization, 3, 367388.

HAMNER, C. W., and D. L. HARNETT (1975): "The Effects of Information and Aspiration Level on Bargaining Behavior," Journal of Experimental Social Psychology, 11, 329-342.

KaGel, J. H., C. Kim, and D. Moser (1996): "Fairness in Ultimatum Games with Asymmetric Information and Asymmetric Payoffs," Games and Economic Behavior, 13, 100-110.

Larson, T., and C. M. CAPRA (2009): "Exploiting Moral Wiggle Room: Illusory Preference for Fairness? A Comment," Judgment and Decision Making, 4, 467474.

LEVINE, D. K. (1998): "Modeling Altruism and Spitefulness in Experiments," Review of Economic Dynamics, 1, 593-622. 
Poulsen, A. U., and M. V. M. Roos (2010): "Do People Make Strategic Moves? Experimental Evidence on Strategic Information Avoidance," Experimental Economics, 13, 206-225.

Poulsen, A. U., and J. H. W. TAN (2007): "Information Acquisition in the Ultimatum Game: An Experimental Study," Experimental Economics, 10, 391-409.

Proctor, R. N. (2008): "Agnotology: A Missing Term to Describe the Cultural Production of Ignorance (and Its Study)," in Agnotology: The Making and Unmaking of Ignorance, ed. by Proctor. R. N., and S. Londa. Stanford: Stanford University Press, 1-36.

Roth, A. E. (1995): "Bargaining Experiments " in Handbook of Experimental Economics ed. by J. H. Kagel, and A. E. Roth. Princton Princton University Press, 253-348.

Roth, A. E., and J. K. Murnighan (1982): "The Role of Information in Bargaining: An Experimental Study," Econometrica, 50, 1123-1142.

Schelling, T. C. (1956): "An Essay on Bargaining," The American Economic Review, 46, 281-306.

— (1960): The Strategy of Conflict. Cambridge, Mass.: Harvard University.

SELTEN, R. (1967): "Die Strategiemethode zur Erforschung des Eingeschränkt Rationalen Verhaltens im Rahmen eines Oligopolexperiments" in Beiträge zur Experimentellen Wirtschaftsforschung ed. by H. Sauermann. Tübingen J.C.B. Mohr 136-168.

SIEGEL, S. and L.E. FOURAKER (1960): Bargaining and Group Decision Making: Experiments in Bilateral Monopoly. New York: McGraw-Hill. 


\section{Appendix}

Figures

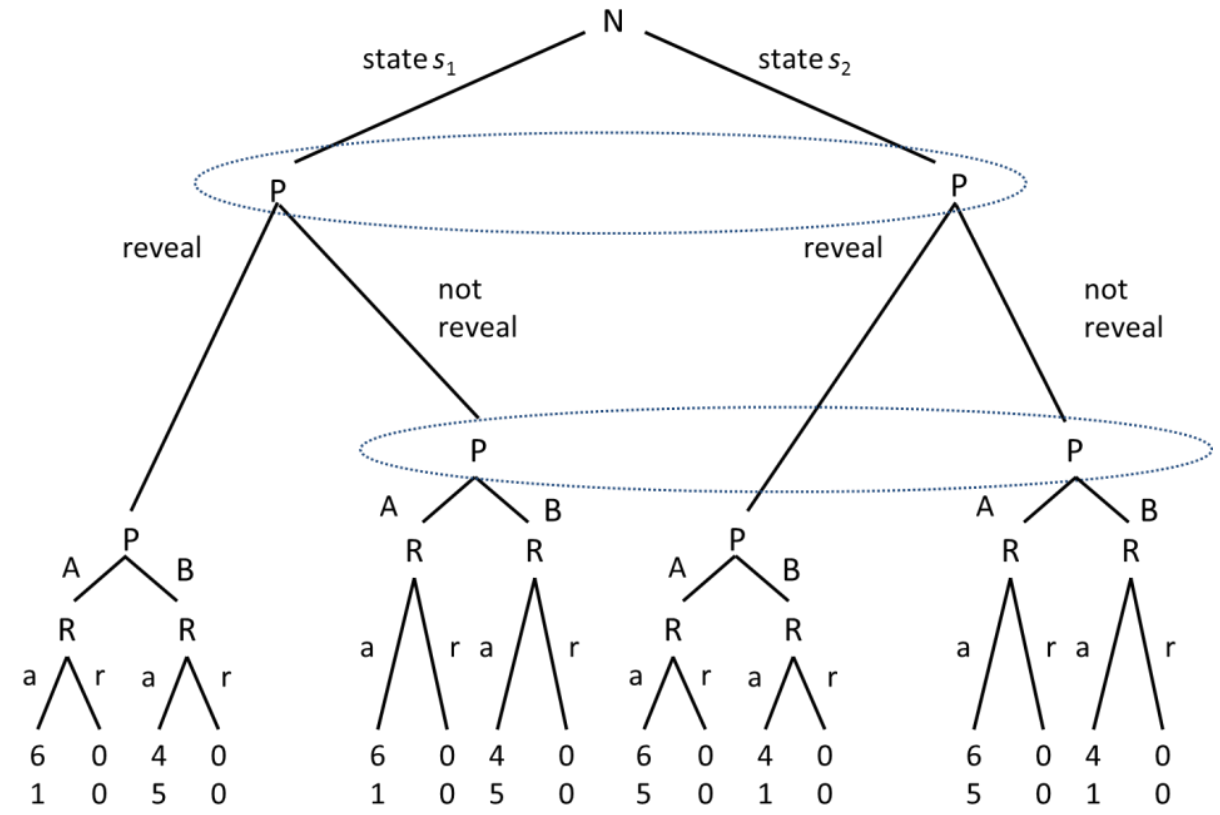

Figure A1: Game-tree of the Choice treatment

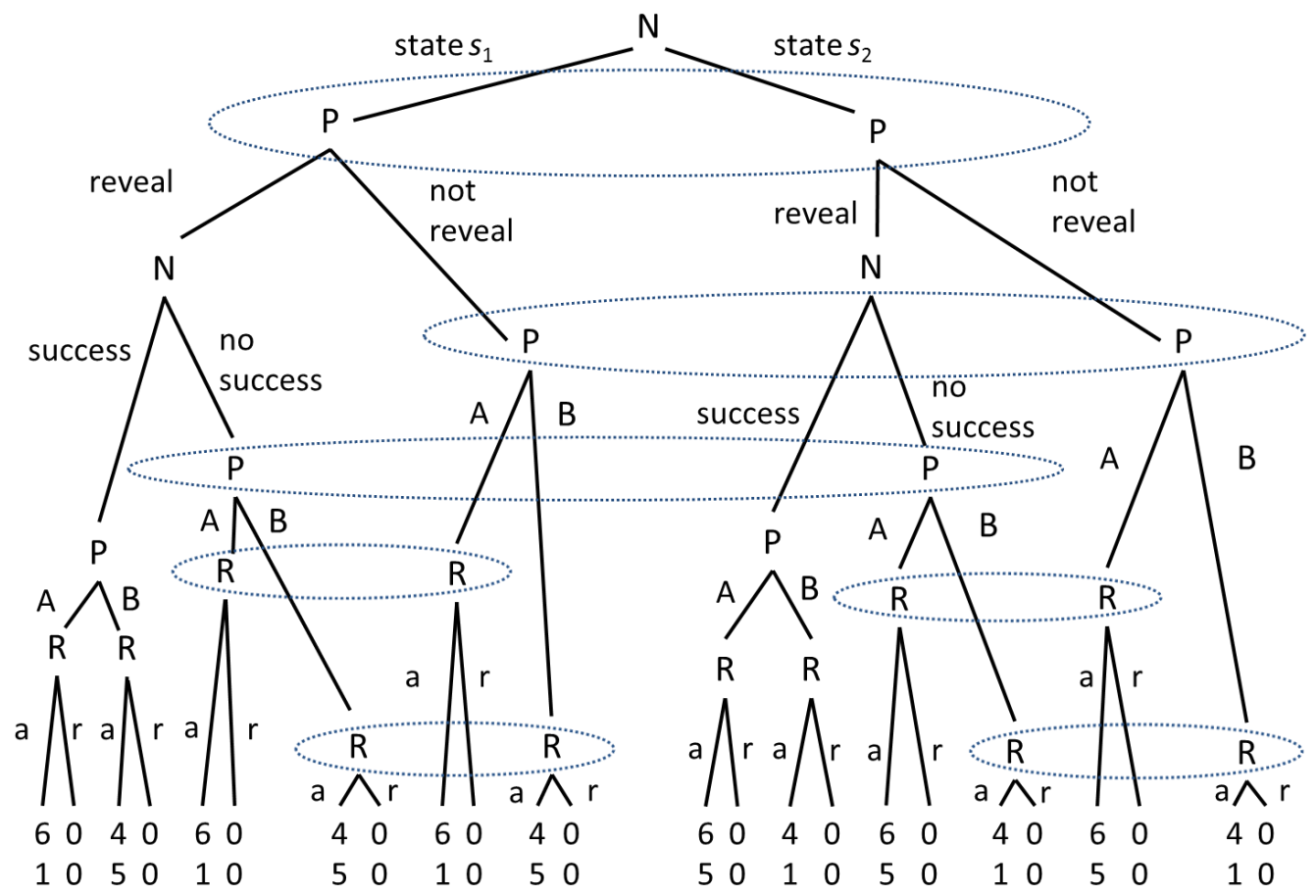

Figure A2: Game-tree of the Choice Uncertain Revelation (Choice-UR) treatment 


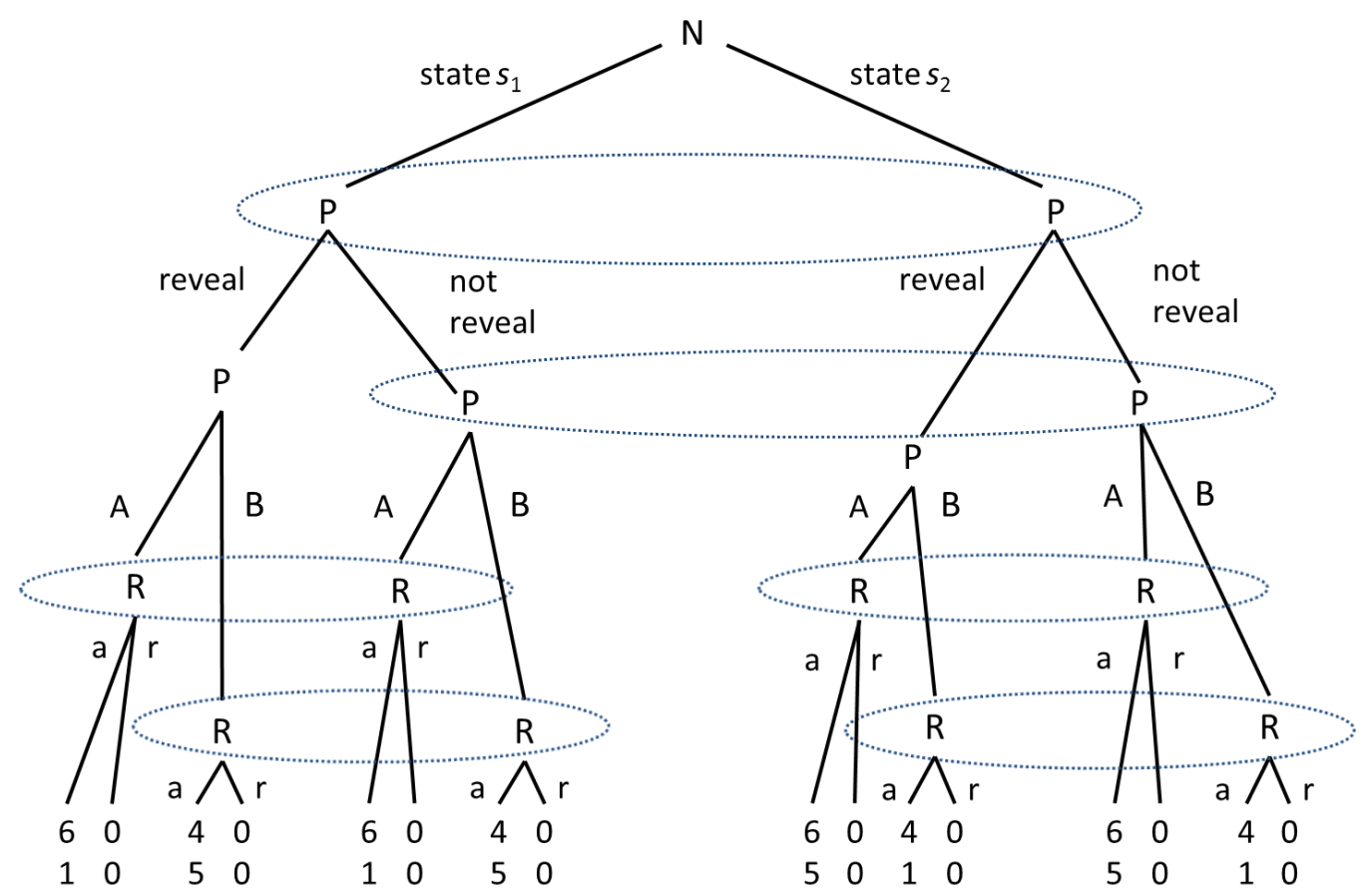

Figure A3: Game-tree of the Choice Hidden (Choice-H) treatment 


\begin{tabular}{|c|c|c|c|c|c|c|c|c|c|}
\hline \multirow[t]{3}{*}{ Treatment } & \multirow[b]{3}{*}{ Proposals / Acceptances Rates } & \multicolumn{4}{|c|}{ Transparent / Revealed } & \multicolumn{4}{|c|}{ Non-Transparent / Not-Revealed } \\
\hline & & \multicolumn{2}{|c|}{ State $s_{1}$} & \multicolumn{2}{|c|}{ State $s_{2}$} & \multicolumn{2}{|c|}{ State $s_{1}$} & \multicolumn{2}{|c|}{ State $s_{2}$} \\
\hline & & Option $A$ & Option $B$ & Option $A$ & Option $B$ & Option $A$ & Option $B$ & Option $A$ & Option $B$ \\
\hline $\begin{array}{c}\text { Transparency } \\
(n=64)\end{array}$ & $\begin{array}{l}\text { Proposer } \\
\text { Responder }\end{array}$ & $\begin{array}{l}9 / 16(56 \%) \\
11 / 16(69 \%)\end{array}$ & $\begin{array}{c}7 / 16(44 \%) \\
16 / 16(100 \%)\end{array}$ & $\begin{array}{l}16 / 16(100 \%) \\
16 / 16(100 \%)\end{array}$ & $\begin{array}{c}0 / 16(0 \%) \\
10 / 16(63 \%)\end{array}$ & $\begin{array}{l}- \\
-\end{array}$ & $\begin{array}{l}- \\
-\end{array}$ & $\begin{array}{l}- \\
-\end{array}$ & $\begin{array}{l}- \\
-\end{array}$ \\
\hline $\begin{array}{c}\text { Non-Transparency } \\
(n=64)\end{array}$ & $\begin{array}{l}\text { Proposer } \\
\text { Responder }\end{array}$ & $\begin{array}{l}- \\
-\end{array}$ & - & $\begin{array}{l}- \\
-\end{array}$ & $\begin{array}{l}- \\
-\end{array}$ & $\begin{array}{l}15 / 16(94 \%) \\
15 / 16(94 \%)\end{array}$ & $\begin{array}{c}1 / 16(6 \%) \\
16 / 16(100 \%)\end{array}$ & $\begin{array}{l}15 / 16(94 \%) \\
16 / 16(100 \%)\end{array}$ & $\begin{array}{c}1 / 16(6 \%) \\
14 / 16(88 \%)\end{array}$ \\
\hline $\begin{array}{l}\text { Choice } \\
(n=190)\end{array}$ & $\begin{array}{l}\text { Proposer } \\
\text { Responder }\end{array}$ & $\begin{array}{c}3 / 35(9 \%) \\
14 / 35(40 \%)\end{array}$ & $\begin{array}{l}32 / 35(91 \%) \\
35 / 35(100 \%)\end{array}$ & $\begin{array}{l}37 / 37(100 \%) \\
37 / 37(100 \%)\end{array}$ & $\begin{array}{c}0 / 37(0 \%) \\
18 / 37(49 \%)\end{array}$ & $\begin{array}{c}12 / 12(100 \%) \\
7 / 12(58 \%)\end{array}$ & $\begin{array}{c}0 / 12(0 \%) \\
12 / 12(100 \%)\end{array}$ & $\begin{array}{l}11 / 11(100 \%) \\
11 / 11(100 \%)\end{array}$ & $\begin{array}{l}0 / 11(0 \%) \\
6 / 11(55 \%)\end{array}$ \\
\hline $\begin{array}{c}\text { Choice-UR } \\
(n=210)\end{array}$ & $\begin{array}{l}\text { Proposer (intentionally ignorant) } \\
\text { Proposer (unintentionally ignorant) }\end{array}$ & $3 / 20(15 \%)$ & $17 / 20(85 \%)$ & $22 / 22(100 \%)$ & $0 / 22(0 \%)$ & $\begin{array}{l}12 / 13(92 \%) \\
16 / 18(89 \%)\end{array}$ & $\begin{array}{l}1 / 13(8 \%) \\
2 / 18(11 \%)\end{array}$ & $\begin{array}{c}12 / 12(100 \%) \\
19 / 20(95 \%)\end{array}$ & $\begin{array}{l}0 / 12(0 \%) \\
1 / 20(5 \%)\end{array}$ \\
\hline & Responder & $8 / 20(40 \%)$ & $20 / 20(100 \%)$ & $21 / 22(95 \%)$ & $14 / 22(63 \%)$ & $21 / 31(68 \%)$ & $31 / 31(100 \%)$ & $31 / 32(97 \%)$ & $24 / 32(75 \%)$ \\
\hline $\begin{array}{c}\text { Choice-H } \\
(n=64)\end{array}$ & $\begin{array}{l}\text { Proposer } \\
\text { Responder }\end{array}$ & $\begin{array}{c}3 / 14(21 \%) \\
-\end{array}$ & $11 / 14(79 \%)$ & $14 / 14(100 \%)$ & $0 / 14(0 \%)$ & $\begin{array}{l}2 / 2(100 \%) \\
8 / 16(50 \%)\end{array}$ & $\begin{array}{c}0 / 2(0 \%) \\
16 / 16(100 \%)\end{array}$ & $\begin{array}{c}2 / 2(100 \%) \\
16 / 16(100 \%)\end{array}$ & $\begin{array}{c}0 / 2(0 \%) \\
12 / 16(75 \%)\end{array}$ \\
\hline
\end{tabular}

Table A1: Proposers' offers and receivers' acceptance rates; note that proposers in the treatment Non-Transparency and proposers who did not reveal in the Choice treatments are not aware of the actual state 


\begin{tabular}{|c|c|c|c|c|}
\hline & $\begin{array}{l}\text { (1) OLS } \\
\text { offer_A }\end{array}$ & $\begin{array}{l}\text { (2) Probit } \\
\text { offer_A }\end{array}$ & $\begin{array}{r}\text { (3) OLS } \\
\text { accept_A }\end{array}$ & $\begin{array}{l}\text { (4) Probit } \\
\text { accept_A }\end{array}$ \\
\hline Non-Transparency & $\begin{array}{c}0.375^{* * *} \\
(0.118)\end{array}$ & $\begin{array}{c}0.470 * * * \\
(0.134)\end{array}$ & $\begin{array}{c}0.249 \\
(0.155)\end{array}$ & $\begin{array}{c}0.320^{* *} \\
(0.126)\end{array}$ \\
\hline Choice_r & $\begin{array}{c}-0.477 * * * \\
(0.101)\end{array}$ & $\begin{array}{c}-0.510 * * * \\
(0.104)\end{array}$ & $\begin{array}{c}-0.288^{* *} \\
(0.129)\end{array}$ & $\begin{array}{c}-0.301 * * \\
(0.134)\end{array}$ \\
\hline Choice_nr & $\begin{array}{c}0.437 * * * \\
(0.127)\end{array}$ & dropped & $\begin{array}{l}-0.105 \\
(0.169)\end{array}$ & $\begin{array}{l}-0.123 \\
(0.184)\end{array}$ \\
\hline Choice-UR_r $r$ & $\begin{array}{c}-0.413 * * * \\
(0.112)\end{array}$ & $\begin{array}{c}-0.401 * * * \\
(0.114)\end{array}$ & $\begin{array}{c}-0.289 * * \\
(0.116)\end{array}$ & $\begin{array}{c}-0.310^{* *} \\
(0.123)\end{array}$ \\
\hline Choice-UR_r_ns & $\begin{array}{c}0.326^{* * * *} \\
(0.115)\end{array}$ & $\begin{array}{c}0.389 * * * \\
(0.148)\end{array}$ & & \\
\hline Choice-UR_nr & $\begin{array}{c}0.361 * * * \\
(0.124)\end{array}$ & $\begin{array}{c}0.439 * * * \\
(0.146)\end{array}$ & $\begin{array}{c}0.157 \\
(0.115)\end{array}$ & $\begin{array}{c}0.164 \\
(0.112)\end{array}$ \\
\hline Choice-H_r & $\begin{array}{c}-0.348 * * * \\
(0.122)\end{array}$ & $\begin{array}{c}-0.330 * * \\
(0.134)\end{array}$ & & \\
\hline Choice-H_nr & $\begin{array}{l}0.437^{*} \\
(0.250)\end{array}$ & dropped & & \\
\hline Choice- $H$ & & & $\begin{array}{l}-0.188 \\
(0.155)\end{array}$ & $\begin{array}{l}-0.206 \\
(0.165)\end{array}$ \\
\hline Constant & $\begin{array}{c}0.563 * * * \\
(0.0833)\end{array}$ & & $\begin{array}{c}0.688^{* * * *} \\
(0.101)\end{array}$ & \\
\hline $\begin{array}{l}\text { Observations } \\
\text { R-squared }\end{array}$ & $\begin{array}{c}146 \\
0.583\end{array}$ & 132 & $\begin{array}{c}146 \\
0.141\end{array}$ & 146 \\
\hline pseudo R-squared & & 0.446 & & 0.117 \\
\hline
\end{tabular}

Table A2: OLS and probit regressions on decisions in state $s_{1}$. Model (1) and (2) explain the effects of the different treatment situations on the proposer's decision to offer option A (offer_A). Model (3) and (4) explain the effect of the different treatment situations on the responder's decision to accept option $A$ (accept_A). Reference category is the Transparency treatment. Independent variables are dummies for different treatment situations. Choice_r $r$ stands for the Choice treatment in which a proposer revealed state $s_{1}$ and Choice_nr stands for a situation in which a proposer did not reveal the state. The same applies for the treatments Choice-UR and Choice-H. Choice-UR_r_ns stands for a situation, in which a proposer tried to reveal but was not successful, i.e., she remained uninformed about the state. Choice- $H$ means a situation where a responder does not know if a proposer revealed the state or not. Standard errors are in parentheses. Levels of significance are indicated as follows: *** $p<0.01, * * p<0.05, * p<0.1$ 


\section{Instructions (translated from German)}

\{[Transparency, Non-Transparency, Choice, Choice-UR, Choice-H]

\section{Instructions}

Welcome and thank for your participation in today's experiment. Please read these instructions carefully. If you have any questions, do not hesitate to raise your hand, we will help you personally.

In this experiment you can earn money. The amount of money you will earn depends on both, your own decisions and the decisions taken by another participant. At the end of the experiment you will receive your payoff in cash. Your payoff is composed out of the experiment's payoff and a show-up fee of $€ 2.50$. You will receive the participation showup fee independently from the payoffs you gain during the experiment.

From now on, we kindly asked you stop all communication. Please make sure that your cell phone is switched off. A violation against these rules may lead to the exclusion from this and other experiments.

\section{The Basic Decision Situation}

In the decision situation there are two types of participants, participant $X$ and participant $\mathrm{Y}$, and two possible cases, case 1 and case 2 . The payoff-tables for both participants are as follows:

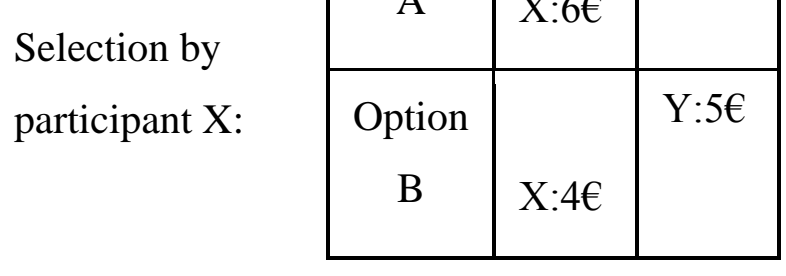

Case 1

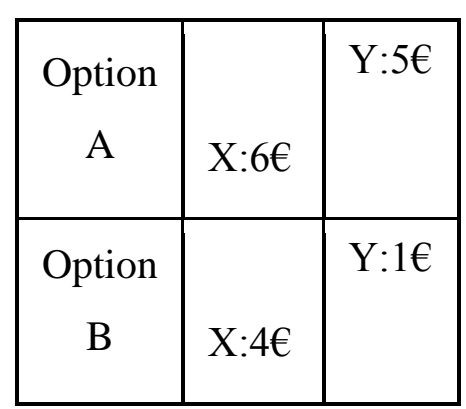

Case 2

One of the two cases will randomly appear. Case 1 and case 2 occur with equal probability. Within each case, two Options exist, Option A and Option B. Participant X chooses one of the two Options. With each respective Option, different payoffs for participant $\mathrm{X}$ and participant $\mathrm{Y}$ are associated. Independently from the occurring case, Option A leads to a payoff of $€ 6$ and Option B to $€ 4$ for participant X. For participant $Y$ different payoffs are associated with the different Options in the different cases. In case of case 1, Option A would lead to a payoff of $€ 1$ and Option B to a payoff of $€ 5$. In the event of case 2, Option A would lead to a payoff of $€ 5$ and Option B to a payoff of $€ 1$. Participant $\mathrm{Y}$ is able to accept or to reject the Option proposed by participant $\mathrm{X}$. If participant $Y$ accepts the Option chosen by participant $X$, both participants receive the respective payoffs. If participants $\mathrm{Y}$ rejects the Option chosen by participant $\mathrm{X}$, both participants receive zero payoffs. 


\section{The Decision Situation in Detail}

At the beginning of the experiment you will be informed via the computer screen which of the two possible roles - either participant X or participant $\mathrm{Y}$ - will be randomly assigned to you. At the same time and again randomly you will be assigned to another participant you will interact with. This assignment is completely anonymous. In each composed pair, one participant has the role of participant $X$ and the other has the role of participant $Y$. The interaction within each pair only occurs through the computers. After you are informed about your role, you can continue by pressing an OK-Button.\}

\{[Transparency] Participant $\mathrm{X}$ takes the first decision. He is informed which of the two possible cases - case 1 or case 2 - have occurred. Thus, he sees one of the two following payoff-tables: \}

\{[Choice, Choice-UR, Choice-H] Participant X takes the first decisions. At the beginning he sees the following buttons. He chooses between the two buttons by pressing one of them:
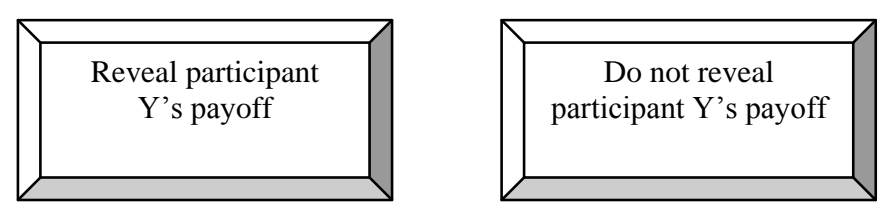

Participant X has two possibilities: He can $\{[$ Choice-UR: try to]\} reveal participant Y's possible payoffs or he cannot reveal, respectively.

If participant $X$ decides for pressing the button "Reveal participant Y's payoff" he sees \{[Choice-UR: with a probability of 50\%]\} one of the two possible payoff-tables:

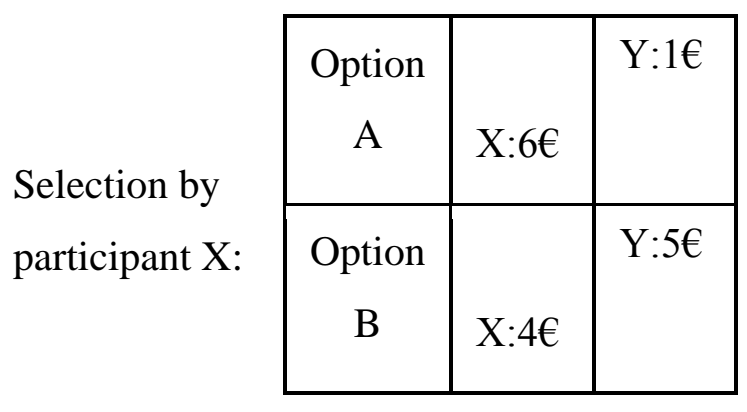

Case 1

\begin{tabular}{|c|l|l|}
\hline $\begin{array}{c}\text { Option } \\
\text { A }\end{array}$ & $\mathrm{X}: 6 €$ & $\mathrm{Y}: 5 €$ \\
\hline $\begin{array}{c}\text { Option } \\
\text { B }\end{array}$ & $\mathrm{X}: 4 €$ & \\
\hline
\end{tabular}

Case 2

Specifically, through pressing the button "Reveal participant Y's payoff", participant X is informed $\{[$ Choice-UR: with a probability of 50\%]\} which of the two possible cases case 1 or case 2 - has occurred. \{[Choice-UR: With a probability of $50 \%$ participant X does not learn which case has occured although he pressed the Button "Reveal participant Y's payoff'. In this case the attempt to reveal participant Y's payoff was not successful and participant $\mathrm{X}$ only sees the following table: 


\section{Selection by \\ participant X:}

\begin{tabular}{|c|c|c|}
\hline $\begin{array}{c}\text { Option } \\
\text { A }\end{array}$ & $\mathrm{X}: 6 €$ & $\mathrm{Y}: ? €$ \\
\hline $\begin{array}{c}\text { Option } \\
\mathrm{B}\end{array}$ & $\mathrm{X}: 4 €$ & $\mathrm{Y}: ? €$ \\
\hline
\end{tabular}

Case 1 or case 2

Here participant $X$ does not know which of the two possible cases has occurred. Instead of participant Y's possible payoffs only a "?" is visible.]\}

$\{[$ Transparency, Choice, Choice-UR, Choice-H] Now, participant X chooses between Option A and Option B. Note that the payoffs for participant X associated with the two cases are identical with respect to the Options. This means participant $\mathrm{X}$ always receives $€ 6$ for Option A and $€ 4$ for Option B provided participant $Y$ accepts the chosen Option. For participant $\mathrm{Y}$ the payoffs in both cases are differently.\}

$\{[$ Non-Transparency $]$ Participant $\mathrm{X}$ takes the first decision. He is not informed which of the two possible cases - case 1 or case 2 - have occurred. Thus, he sees the two following payoff-table:]\}

$\{[$ Choice, Choice-UR, Choice-H] If participant X decides for pressing the button "Do not reveal participant Y's payoff' he sees the following payoff-table:

Selection by
participant X:

\begin{tabular}{|c|c|c|}
\hline $\begin{array}{c}\text { Option } \\
\text { A }\end{array}$ & $\mathrm{X}: 6 €$ & $\mathrm{Y}: ? €$ \\
\hline $\begin{array}{c}\text { Option } \\
\text { B }\end{array}$ & $\mathrm{X}: 4 €$ & $\mathrm{Y}: ? €$ \\
\hline
\end{tabular}

Case 1 or case 2

Participant $\mathrm{X}$ then decides not to know the possible payoffs for participant $\mathrm{Y}$.\} $\{[$ Non-Transparency, Choice, Choice-UR, Choice-H] Specifically he is not informed if case 1 or case 2 occurred. Instead of participant Y's possible payoffs only a "?" is visible. But participant $X$ knows that he receives a payoff of $€ 6$ for Option A and a payoff of $€ 4$ for Option B if participant $Y$ accepts his decision. Participant $X$ then chooses between Option A and Option B.\} 
\{[Transparency, Non-Transparency, Choice, Choice-UR, Choice-H] Participant Y will be informed which of the cases - case 1 or case 2 - have occurred.\} [\{Choice] At the same time he is $\{[$ Choice $-H]$ not $\}$ informed if participant $\mathrm{X}$ revealed participant $\mathrm{Y}$ 's possible payoffs or if he covered it. Thus, he will be $\{[$ Choice $-H]$ not $\}$ informed if participant $\mathrm{X}$ knew the possible payoffs for participant $\mathrm{Y}$ associated with the Option chosen. $\{[$ Choice-UR] If participant $\mathrm{X}$ was uninformed about participant $\mathrm{Y}$ 's payoff this can be due to two reasons: either participant was not successful revealing participant $Y$ 's possible payoffs or participant $X$ decided not to reveal participant $Y$ 's possible payoffs. If participant $\mathrm{X}$ was uninformed participant $\mathrm{Y}$ will not be informed due to which reason participant X became uninformed.\} \{[Transparency, Non-Transparency, Choice, Choice$U R$, Choice-H] Participant Y now decides for both possible Options of participant X - so for Option A and Option B - if he accepts or rejects participant X's choice. Depending on the Option actually chosen by participant X, payoffs for both participants are determined. If participant $\mathrm{Y}$ accepts the Option chosen by participant $\mathrm{X}$, both participants receive their respective payoffs. If participant $\mathrm{Y}$ rejects the Option chosen, both participants receive zero payoffs. $\}$

\{\}$=$ Indicate the phrase that is exclusively employed in the respective treatment, [Transparency], [Non-Transparency], [Choice], [Choice-UR] or [Choice-H]. 


\section{Questionnaire}

\section{Questions of Comprehension}

Please answer the following questions. If you have a question, raise your hand, we will help personally.

\section{For the following questions, assume that case 1 has occurred:}

What is the payoff for participant $\mathrm{X}$ and participant $\mathrm{Y}$ if participant $\mathrm{X}$ chooses Option $\mathrm{A}$ and participant $\mathrm{Y}$ accepts this choice? Participant X Participant Y What is the payoff for participant $\mathrm{X}$ and participant $\mathrm{Y}$ if participant $\mathrm{X}$ chooses Option $\mathrm{A}$ and participant $\mathrm{Y}$ rejects this choice? Participant $\mathrm{X}$ Participant Y What is the payoff for participant $\mathrm{X}$ and participant $\mathrm{Y}$ if participant $\mathrm{X}$ chooses Option $\mathrm{B}$ and participant $\mathrm{Y}$ accepts this choice? Participant X Participant $\mathrm{Y}$ What is the payoff for participant $\mathrm{X}$ or participant $\mathrm{Y}$ if participant $\mathrm{X}$ chooses Option $\mathrm{B}$ and participant $\mathrm{Y}$ rejects this choice?

For the following questions, assume that case 2 has occurred:

What is the payoff for participant $\mathrm{X}$ and participant $\mathrm{Y}$ if participant $\mathrm{X}$ chooses Option $\mathrm{A}$ and participant $\mathrm{Y}$ accepts this choice? Participant X Participant Y What is the payoff for participant $\mathrm{X}$ and participant $\mathrm{Y}$ if participant $\mathrm{X}$ chooses Option $\mathrm{A}$ and participant $\mathrm{Y}$ rejects this choice? Participant $\mathrm{X}$ Participant Y What is the payoff for participant $\mathrm{X}$ and participant $\mathrm{Y}$ if participant $\mathrm{X}$ chooses Option $\mathrm{B}$ and participant $\mathrm{Y}$ accepts this choice? Participant $\mathrm{X}$ Participant Y What is the payoff for participant $\mathrm{X}$ and participant $\mathrm{Y}$ if participant $\mathrm{X}$ chooses Option $\mathrm{B}$ and participant $\mathrm{Y}$ rejects this choice?

Participant X

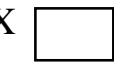

Participant Y

\section{Please specify for the following statements if they are right or wrong:}

Participant $\mathrm{X}$ always receives $€ 6$ for Option A and $€ 4$ for Option B if participant $\mathrm{Y}$ accepts the Option chosen by participant $\mathrm{X}$ ! Right $\square$ Wrong Participant $\mathrm{Y}$ always receives $€ 1$ for Option $A$ and $€ 5$ for Option B if he accepts the Option chosen by participant X!

Right $\square$ Wrong

The probability that case 1 or case 2 occurs is exactly the same!

Right $\square$ Wrong 